\title{
Reliability and Validity of the Arabic Version of the EORTC QLQ-C30 and QLQ-BR23 Questionnaires
}

This article was published in the following Dove Press journal: Neuropsychiatric Disease and Treatment

\author{
Ghufran Jassim $\mathbb{D}^{\prime}$ \\ Ahmed AlAnsari ${ }^{2}$ \\ 'Department of Family Medicine, Royal \\ College of Surgeons in Ireland-Medical \\ University of Bahrain, Busaiteen, \\ Kingdom of Bahrain; ${ }^{2}$ Quality \\ Enhancement Office, Royal College of \\ Surgeons in Ireland-Medical University of \\ Bahrain, Busaiteen, Bahrain
}

Objective: To evaluate the psychometric properties of the Arabic version of the EORTC QLQ-C30 and EORTC QLQ-BR23 questionnaires.

Materials and Methods: A cross-sectional study was carried out. A total of 337 subjects were recruited from the Oncology Centre in Bahrain and 239 consented to participation. The European Organization for Research and Treatment-QOL questionnaire and breast cancerspecific module (EORTC QLQ-C30 and QLQ-BR23) were used to measure the HRQOL among women with breast cancer. All statistical tests were performed using SPSS Version 20. The reliability of the EORTC QLQ-C30 and QLQ-BR23 questionnaires was examined using Cronbach's alpha test. The construct validity of both questionnaires was tested using the exploratory factor analysis.

Results: Exploratory factor analysis results of EORTC QLQ-C30 showed that KaiserMeyer-Olkin (KMO) measure of sampling adequacy was 0.878 and Bartlett's Test of Sphericity is $<0.001$. The extracted four-factor model explained $51.52 \%$ of the total variance. Relating to EORTC-QLQ-BR23, the KMO value was 0.735 and Bartlett's Test of Sphericity showed a significance of $\mathrm{p}<0.001$ and extracted a three-factor model which explained a total variance of 46.05\%. The Cronbach's alpha coefficient results for EORTC QLQ-C30 and QLQ BR-23 were 0.927 and 0.844 respectively which reflects high internal consistency.

Conclusion: The EORTC QLQ-C30 and QLQ-BR23 questionnaires are feasible and promising instruments to measure the levels of HRQOL among Arabic-speaking women with breast cancer in future studies with some suggested modifications in some of the domains or items.

Keywords: quality of life, breast cancer, validity, EORTC, QLQ

\section{Introduction}

Cancer is expected to rank as the leading cause of death and the single most important barrier to increasing life expectancy in every country of the world in the twenty-first century. Breast cancer remains the most common type of cancer in women. ${ }^{1}$ The symptoms of cancer itself, its treatment and complications have a substantial impact on patient's quality of life. ${ }^{2}$ Heath-related quality of life (HRQOL) is a multidimensional construct that has proven difficult to define. Generally, HRQOL covers the subjective perceptions of cancer patients' symptoms, including physical, emotional, social, and cognitive functions and, importantly, disease symptoms and side effects of treatment. It is perceived to be as important as survival in making treatment decision and thus, health-related quality of life has
Correspondence: Ghufran Jassim Department of Family Medicine, Royal College of Surgeons in IrelandMedical University of Bahrain, PO Box 15503, Adliya, Kingdom of Bahrain Email gjassim@rcsi-mub.com 
become a more accurate predictor of survival than some other clinical parameters, such as performance status. ${ }^{3}$

The two well-known and widely used QOL instruments that have been validated across cultures for breast cancer are the European Organization for Research and Treatment (EORTC) QLQ-C30 and QLQ-BR23 measures. ${ }^{4}$

The QLQ-C30 questionnaire was developed in 1980 by European Organization for Research and Treatment of Cancer (EORTC) and consists of 30 items. EORTCBR23 was developed by Spranger et al specifically for breast cancer patients which must be used in combination with EORTC-C30 and consists of 23 items. ${ }^{5}$ The translated Arabic version of the questionnaire is available from the EORTC website. ${ }^{6}$

Many studies evaluated the quality of life of breast cancer survivors. In Bahrain, quality of life of breast cancer survivors has been reported in a cross-sectional study on 337 Bahraini women with breast cancer and in a qualitative study on 12 patients. ${ }^{7,8}$

Breast cancer is ranked as the most prevalent cancer among women in Bahrain. Statistics revealed that the women aged less than 40 years make up a larger percentage of total breast cancer cases than do their counterparts in Western countries. ${ }^{9}$ A review of the epidemiological pattern of breast cancer in Bahrain between 2000 and 2010 revealed that the median age at diagnosis during the 11-year period was 49 years with the highest percentage of cases occurring in the age group 45-49. ${ }^{10}$ In addition, Bahraini women similar to other Arab women face cultural taboos surrounding breast cancer. ${ }^{9,11}$

Ranking as the most prevalent cancer among women in the Arab world, the younger age at diagnosis and the unique cultural norms and values all suggest that information on quality of life (QoL) in this region may be specific and hence important to both health care providers and patients. Therefore, it would be necessary to evaluate the appropriateness of using the EORTC-C30 and BR23 questionnaires in Bahrain as the cultural and social context may be different from the socio-cultural setting of other countries.

Few studies has evaluated the psychometric properties of the Arabic version of the two questionnaires. ${ }^{12-16}$ However, they were either conducted on a non-probability sample of cancer survivors or included a small sample size or used local spoken language rather than the official Arabic language. ${ }^{16,17}$ Further, none of these studies conducted exploratory factor analysis to assess construct validity, although it is considered one of the strongest approaches to establishing construct validity, and is the most commonly used method for establishing construct validity measured by an instrument. ${ }^{18}$ The only exception is the Lebanese study which used confirmatory rather than exploratory factor analysis. $^{15}$

The objective of this study is to evaluate the psychometric properties of the Arabic version of the EORTC QLQ-C30 and EORTC QLQ-BR23 questionnaires on a representative sample of women with breast cancer at different stages of diagnosis and different times of survival.

Our specific objectives are to assess: (i) internal consistency of the EORTC QLQ-C30 and BR23 (ii) item-total correlation and (iii) exploratory factor analysis.

\section{Methods}

This was a cross-sectional study on a random sample of 337 Bahraini women with breast cancer. The sample was drawn from the Bahrain Cancer Registry across a 9-year period. Data were collected over a period of 2 months in 2018. Quality of life was assessed using the Arabic version of the European Organization for Research and Treatment of Cancer QoL Cancer-Specific Version (EORTC QLQC30, v.3.0) and breast cancer-specific EORTC QLQBR23. Sampling and recruitment are described explicitly in the original study. ${ }^{7}$ Ethical approval was sought from an RCSI Bahrain and Ministry of health ethics committees.

The QLQ-C30 consists of 30 items measuring Global Health status (2 items), Functional scales (15 items) and Symptoms scales/items (13 items). Items were measured using a 4-point Likert Scale ranging from Not at all (1) to Very much (4) (Table 1).

EORTC-BR23 consists of 23 items which measure two main scales "Functional Scale ( 8 items) and "Symptoms scales (15 items). Items measured using 4-point Likert Scale ranging from Not at all (1) to Very much (4) (Table 2).

We followed the supplemental scoring manual in the analysis. As instructed in the manual, scores were transformed to range from 0 to 100 in order to standardise the raw score. A higher score represents a higher (better) level of functioning or a higher (worse) level of symptoms. The Statistical Package for the Social Sciences SPSS was used for analysis.

The reliability (internal consistency) of the whole instrument and the separate scales were measured using Cronbach's alpha whereas construct validity was measured using the exploratory factor analysis which was done using principal component analysis method with varimax rotation. 
Table I Scoring the QLQ-C30 Version 3.0

\begin{tabular}{|c|c|c|c|}
\hline & $\begin{array}{l}\text { Number of } \\
\text { Items }\end{array}$ & $\begin{array}{l}\text { Item } \\
\text { Range }\end{array}$ & $\begin{array}{l}\text { Version } 3.0 \text { Item } \\
\text { Numbers }\end{array}$ \\
\hline $\begin{array}{l}\text { Global health status/ } \\
\text { QoL } \\
\text { Functional scales }\end{array}$ & 2 & 6 & 29,30 \\
\hline Physical Functioning & 5 & 3 & $1-5$ \\
\hline Role functioning & 2 & 3 & 6,7 \\
\hline Emotional functioning & 4 & 3 & $21-24$ \\
\hline Cognitive functioning & 2 & 3 & 20,25 \\
\hline Social functioning & 2 & 3 & 26,27 \\
\hline \multicolumn{4}{|l|}{$\begin{array}{l}\text { Symptoms scales/ } \\
\text { items }\end{array}$} \\
\hline Fatigue & 3 & 3 & $10,12,18$ \\
\hline Nausea and vomiting & 2 & 3 & 14,15 \\
\hline Pain & 2 & 3 & 9,19 \\
\hline Dyspnoea & 1 & 3 & 8 \\
\hline Insomnia & I & 3 & 11 \\
\hline Appetite loss & 1 & 3 & 13 \\
\hline Constipation & 1 & 3 & 16 \\
\hline Diarrhoea & I & 3 & 17 \\
\hline Financial difficulties & I & 3 & 28 \\
\hline
\end{tabular}

Table 2 Scoring the QLQ-BR 23

\begin{tabular}{|c|l|l|l|}
\hline & $\begin{array}{l}\text { Number of } \\
\text { Items }\end{array}$ & $\begin{array}{l}\text { Item } \\
\text { Range }\end{array}$ & $\begin{array}{l}\text { Version 3.0 Item } \\
\text { Numbers }\end{array}$ \\
\hline Functional scales & & & \\
Body image & 4 & 3 & $39-42$ \\
$\quad$ Sexual functioning & 2 & 3 & 44,45 \\
Sexual enjoyment & 1 & 3 & 46 \\
$\quad$ Future perspective & 1 & 3 & 43 \\
\hline Symptoms scales/ & & & \\
items & & & \\
Systemic side effect & 7 & 3 & $31-34,36-38$ \\
Breast symptoms & 4 & 3 & $50-53$ \\
Arm symptoms & 3 & 3 & $47-49$ \\
Upset by hair loss & 1 & 3 & 35 \\
\hline
\end{tabular}

The data were first checked for suitability and adequacy for exploratory factor analysis using Kaiser-Meyer-Olkin (KMO) measure and Bartlett's Test of Sphericity. A factor loading was considered good in this study if the item correlation was $>0.40 .{ }^{19}$ The statistical package for social sciences (SPSS) version 25 was used to analyze the data.

\section{Results}

\section{Demographics and Clinical Data of Participants}

A random sample of 337 was drawn from Bahrain Cancer Registry. Among the sample taken from the registry, 18 had died and 66 were inaccessible. Seven were ineligible due to language barrier, deafness or wrong diagnosis, and seven refused to participate (reasons for not participating were lack of time, extreme anxiety, unwillingness to share their experience or not wanting to be reminded of their experience with cancer). Two hundred and thirty-nine women consented to participate and were interviewed by the researcher (recruitment rate $71 \%$ ). The mean age of participants was $50.2(\mathrm{SD} \pm 11.1)$ years, respectively. Mean time elapsed since diagnosis was $4.22(\mathrm{SD} \pm 2.69)$ years. About one-third finished high school or diploma $34.4 \%, 62 \%$ were not employed, 46.6 were premenopausal, $38 \%$ postmenopausal, $45 \%$ were at stage II of the disease and $25 \%$ were at stage III or IV. Participants had a mean score for global health of 63.9 (95\% CI 61.2-66.6). Among functional scales, social functioning scored the highest (77.5 [95\% CI 73.65-81.38]) whereas emotional functioning scored the lowest (63.4 [95\% CI 59.12-67.71]). The most distressing symptom on the symptom scales was fatigability (Mean 35.2 [95\% CI 31.38-39.18]) followed by sleep disturbance and pain. Using the disease-specific tool it was found that sexual functioning scored the lowest (Mean 25.9 [95\% CI 70.23-77.90]) indicating poor functioning whereas body image scored the highest (Mean 75.64 [95\% CI 71.79-79.48]). On the symptom scale, upset due to hair loss scored the highest (Mean 46.3 [95\% CI 37.82-54.84]) indicating worse functioning followed by arm symptoms (Mean 36.58 [95\% CI 32.50-40.65]).

\section{EORTC QLQ-30 (Version 3.0)}

Average time to complete the questionnaire was 11 minutes. Items 29 and 30 assessing the Global Health Status were excluded from the analysis as the scales were ranging from 1 to 6 (Very poor to Excellent) while the remaining 28 items were measured on a 4-point Likert Scale (Not at all to Very much).

\section{Factor Analysis}

Exploratory factor analysis (with Varimax rotation) showed that Kaiser-Meyer-Olkin (KMO) measure of sampling adequacy was 0.878 (above the commonly recommended value of 0.6), and Bartlett's Test of Sphericity was significant $<0.00$. This indicates that a factor analysis may be useful with our data and that the variables are related and therefore suitable for structure detection. The four factors explained $51.52 \%$ of the total variance. Item 28 (Has your physical condition or medical treatment caused you financial difficulties?) did not load any of the four 
factors and was removed from further analyses. Table 3 explains the factors loading.

The first factor loaded significantly, with the exception of Q5, all items of physical scale (Q1, Q2, Q3, Q4) and role $(\mathrm{Q} 6, \mathrm{Q} 7)$ scales with factor loading ranging from 0.31 to 0.71 ; the second factor loaded significantly all items of emotional scale (Q21, Q22, Q23, Q24) with factor loading ranging from 0.31 to 0.85 . The third factor loaded significantly all items of pain and fatigue (Q9, Q19, Q18) and cognitive scale (Q20, Q25) with factor loading ranging from 0.30 to 0.75 . The fourth factor loaded significantly all items of appetite loss (Q13), nausea and vomiting (Q14), constipation (Q16) and diarrhoea (Q17) scales with factor loading ranging from 0.31 to 0.080 .

\section{Internal Consistency Reliability}

We checked the overall reliability of the instrument and the four factors separately. The overall reliability of the 27-item instrument was 0.927 . Table 4 explains the four factors' reliability and item-total correlation for each factor. Factor 1 yielded the highest coefficient amongst all (0.88) whereas the lowest was reported for factor $4(0.70)$.

The inter-scale correlation of EORTC QLQ-C30 was tested and presented in Table 5. Factors 1 and 3 showed the highest correlation coefficient $(0.60)$. The inter-scale correlations for the EORTC QLQ-C30 ranged from 0.39 (p $<0.01)$ between factor 2 and factor 4 to $0.60(\mathrm{P}<0.01)$ between factor 1 and factor 3 .

\section{EORTC-QLQ-BR23}

\section{Factor Analysis}

The instrument was suitable for the analysis and the sample was adequate for an exploratory factor analysis demonstrated by the KMO value of 0.735 and Bartlett's Test of Sphericity significance of $(p<0.001)$. The exploratory factor analysis was done using principal component analysis method with varimax rotation and extracted a three-factor model, which explained a total variance of $46.05 \%$.

Factor loading is presented in Table 6 and shows that factor 1 loaded significantly all items of body image scale (Q39, Q40, Q41, Q42) with factor loading ranging from 0.39 to 0.80 . Factor 2 loaded significantly all items of arm symptoms (Q47, Q48, Q49) and breast symptom scales (Q50, Q51, Q52, Q53) with factor loading ranging from 0.44 to 0.77 . Factor 3 loaded significantly almost all items of systemic side effect scale (Q31, Q32, Q34, Q36, Q37) with factor loading ranging from 0.38 to 0.73 .
Table 3 Exploratory Factor Analysis

\begin{tabular}{|c|c|c|c|c|}
\hline \multicolumn{5}{|c|}{ Components } \\
\hline Items & $\begin{array}{l}\text { Factor I } \\
\text { (Physical } \\
\text { and Role) }\end{array}$ & $\begin{array}{l}\text { Factor } 2 \\
\text { (Emotion) }\end{array}$ & $\begin{array}{l}\text { Factor } 3 \\
\text { (Pain and } \\
\text { Cognition) }\end{array}$ & $\begin{array}{l}\text { Factor } 4 \\
\text { (Systemic } \\
\text { Symptoms) }\end{array}$ \\
\hline QI & 0.622 & & & \\
\hline Q2 & 0.712 & & & \\
\hline Q3 & 0.593 & & & \\
\hline Q4 & 0.520 & & & \\
\hline Q5 & & & & 0.438 \\
\hline Q6 & 0.686 & & & \\
\hline Q7 & 0.687 & & & \\
\hline Q8 & 0.556 & & & \\
\hline Q9 & & & 0.545 & \\
\hline Q10 & 0.700 & & & \\
\hline QII & 0.440 & & & \\
\hline Q12 & 0.596 & & & \\
\hline Q13 & & & & 0.555 \\
\hline Q14 & & & & 0.757 \\
\hline Q15 & & & & 0.800 \\
\hline Q16 & & & & 0.494 \\
\hline Q17 & & & & \\
\hline Q18 & & & 0.500 & \\
\hline Q19 & & & 0.730 & \\
\hline Q20 & & & 0.759 & \\
\hline Q21 & & 0.844 & & \\
\hline Q22 & & 0.859 & & \\
\hline Q23 & & 0.678 & & \\
\hline Q24 & & 0.631 & & \\
\hline Q25 & & & 0.618 & \\
\hline Q26 & & 0.464 & & \\
\hline Q27 & & 0.485 & & \\
\hline
\end{tabular}

Note: The bold font indicates that Cronbach alpha values of 0.5 or higher represent acceptable internal consistency.

\section{Internal Consistency Reliability}

The overall reliability of the instrument was 0.844 , which is higher than the minimum required 0.70 . The reliability of each item is explained in Table 4 and shows that factor 1 has the highest reliability (Cronbach's alpha 0.79).

Item 35 (Were you upset by the loss of your hair?) did not load on any of the factors. During the reliability analysis items 38 (Did you have headaches?), 44 (To what extent were you interested in sex?), 45 (To what extent were you sexually active?) and 46 (To what extent was sex enjoyable for you?) were removed because of the low reliability.

Table 7 presents the inter-scale correlation of BR23 and shows that factors 1 and 2 has the highest correlation coefficient (0.466). 
Table 4 Reliability Analysis: Internal Consistency Reliability and Item-Total Correlation

\begin{tabular}{|c|c|c|c|c|c|}
\hline Factors & Items & Mean & SD & Corrected Item Total Correlation & Cronbach's Alpha \\
\hline \multirow[t]{10}{*}{ Factor I (Physical and role) } & QI & 2.41 & 1.210 & 0.539 & \multirow[t]{10}{*}{$0.88 \mathrm{I}$} \\
\hline & Q2 & 2.33 & 1.212 & 0.643 & \\
\hline & Q3 & 1.41 & 0.862 & 0.548 & \\
\hline & Q4 & 1.54 & 0.890 & 0.456 & \\
\hline & Q6 & 1.97 & 1.119 & 0.694 & \\
\hline & Q7 & 1.90 & 1.129 & 0.703 & \\
\hline & Q8 & 1.61 & 0.912 & 0.627 & \\
\hline & Q10 & 2.13 & 1.039 & 0.724 & \\
\hline & QII & 1.91 & 1.181 & 0.508 & \\
\hline & Q12 & 2.18 & 1.122 & 0.682 & \\
\hline \multirow[t]{6}{*}{ Factor 2 (Emotions) } & Q21 & 2.20 & 1.190 & 0.793 & \multirow[t]{6}{*}{0.842} \\
\hline & Q22 & 2.19 & 1.176 & 0.796 & \\
\hline & Q23 & 2.13 & 1.136 & 0.612 & \\
\hline & Q24 & 1.81 & 1.163 & 0.651 & \\
\hline & Q26 & I.7I & 1.107 & 0.403 & \\
\hline & Q27 & 1.64 & 1.094 & 0.479 & \\
\hline \multirow[t]{5}{*}{ Factor 3 (Pain and cognition) } & Q9 & 2.01 & 1.061 & 0.575 & \multirow[t]{5}{*}{0.808} \\
\hline & Q18 & 1.88 & 1.101 & 0.591 & \\
\hline & Q19 & 1.77 & 1.091 & 0.663 & \\
\hline & Q20 & 1.66 & 1.013 & 0.681 & \\
\hline & Q25 & 1.93 & 1.039 & 0.467 & \\
\hline \multirow[t]{6}{*}{ Factor 4 (Systemic side effect) } & Q5 & 1.04 & 0.281 & 0.587 & \multirow[t]{6}{*}{0.700} \\
\hline & Q13 & 1.40 & 0.830 & 0.624 & \\
\hline & Q14 & 1.36 & 0.759 & 0.352 & \\
\hline & Q15 & 1.18 & 0.604 & 0.319 & \\
\hline & Q16 & 1.54 & 0.921 & 0.225 & \\
\hline & Q17 & 1.21 & 0.570 & 0.510 & \\
\hline
\end{tabular}

Table 5 Inter-Scale Correlations of EORTC QLQ-C30

\begin{tabular}{|l|l|l|l|l|}
\hline & Factor I (Physical) & Factor 2 (Emotion) & Factor 3 (Cognition) & Factor 4 (Systemic Side Effect) \\
\hline Factor I (Physical) & $\mathrm{I}$ & & & \\
Factor 2 (Emotion) & $0.512^{* *}$ & $\mathrm{I}$ & & \\
Factor 3 (Cognition) & $0.604^{* *}$ & $0.549^{* *}$ & 1 & \\
Factor 4 (Systemic side effect) & $0.438^{* *}$ & $0.394^{* *}$ & $0.426^{* *}$ & 1 \\
\hline
\end{tabular}

Note: ${ }^{* *}$ Correlation is significant at the 0.01 level (2-tailed).

\section{Discussion}

This study assessed the reliability and construct validity of the EORTC QLQ-C30 and BR32 in a sample of 337 Bahraini women with breast cancer. Internal consistency reliability revealed high correlation coefficients for the total scale of both QLQ-C30 and BR32 (0.927 and 0.844, respectively) indicating good overall internal consistency. Our results were similar and confirmative in the area of reliability with other reported studies in Kuwait, ${ }^{12}$ United Arab of Emirates, ${ }^{13}$ Qatar, ${ }^{14}$ Morocco $^{16,17}$ and in Lebanon. ${ }^{15}$
In this study, the coefficient was estimated for each multi-item scale of the EORTC QLQ-C30 and showed coefficients ranging between 0.22 and 0.79 . The lowest $(<0.4)$ was reported for questions: 15, 16, and 17. For BR32, the coefficients of each item ranged between 0.29 and 0.66 with the lowest $(<0.4)$ reported for questions 33 , 34, 36, 43 and 51.

Items 44 (To what extent were you interested in sex?), 45 (To what extent were you sexually active?) and 46 (To what extent was sex enjoyable for you?) were removed 
Table 6 EORTC-QLQ-BR23: Exploratory Factor Analysis Factor Loadings and Reliability Analysis: Internal Consistency Reliability and Item-Total Correlation

\begin{tabular}{|c|c|c|c|c|c|c|c|}
\hline \multirow[t]{2}{*}{ Items } & \multirow[t]{2}{*}{ Mean } & \multirow[t]{2}{*}{ SD } & \multicolumn{3}{|l|}{ Factors } & \multirow{2}{*}{$\begin{array}{l}\text { Corrected Item-Total } \\
\text { Correlation }\end{array}$} & \multirow{2}{*}{$\begin{array}{l}\text { Cronbach's } \\
\text { Alpha }\end{array}$} \\
\hline & & & $\begin{array}{l}\text { Factor I } \\
\text { (Body Image) }\end{array}$ & $\begin{array}{l}\text { Factor2 (Arm and } \\
\text { Breast Symptoms) }\end{array}$ & $\begin{array}{l}\text { Factor3 (Systemic } \\
\text { Side Effect) }\end{array}$ & & \\
\hline Q31 & 1.85 & 1.074 & & & 0.529 & 0.404 & 0.635 \\
\hline Q32 & 1.32 & 0.776 & & & 0.737 & 0.479 & \\
\hline Q33 & 1.4 & 0.757 & & & 0.389 & 0.294 & \\
\hline Q34 & 1.71 & 1.038 & & & 0.524 & 0.310 & \\
\hline Q36 & 1.62 & 0.937 & & & 0.529 & 0.367 & \\
\hline Q37 & 1.2 & 0.637 & & & 0.534 & 0.407 & \\
\hline Q39 & 1.71 & 1.085 & 0.782 & & & 0.661 & 0.795 \\
\hline Q40 & 1.79 & 1.121 & 0.799 & & & 0.662 & \\
\hline Q4I & 1.78 & 1.136 & 0.803 & & & 0.653 & \\
\hline Q42 & 1.65 & 1.043 & 0.780 & & & 0.604 & \\
\hline Q43 & 2.16 & 1.185 & 0.396 & & & 0.335 & \\
\hline Q47 & 2.48 & 1.181 & & 0.544 & & 0.618 & 0.775 \\
\hline Q48 & 1.79 & 1.097 & & 0.497 & & 0.486 & \\
\hline Q49 & 2.03 & I.I47 & & 0.616 & & 0.660 & \\
\hline Q50 & 1.74 & 0.937 & & 0.633 & & 0.519 & \\
\hline Q5I & 1.22 & 0.587 & & $0.44 I$ & & 0.334 & \\
\hline Q52 & 1.3 & 0.701 & & 0.777 & & 0.467 & \\
\hline Q53 & 1.39 & 0.789 & & 0.677 & & 0.424 & \\
\hline
\end{tabular}

Note: The bold font indicates that Cronbach alpha values of 0.5 or higher represent acceptable internal consistency.

Table 7 Inter-Scale Correlations of EORTC QLQ-BR23

\begin{tabular}{|l|l|l|l|}
\hline Factors & Factor I (Body Image) & Factor 2 (Arm and Breast Symptoms) & Factor 3 (Systemic Side Effect) \\
\hline Factor I (Body image) & $\mathrm{I}$ & $0.466^{* *}$ & $0.389 * *$ \\
Factor 2 (Arm and breast symptoms) & & $\mathrm{I}$ & $0.316^{* * *}$ \\
Factor 3 (Systemic side effect) & & & 1 \\
\hline
\end{tabular}

Notes: **Correlation is significant at the 0.01 level (2-tailed).

from reliability analysis because of very low coefficient values. This is not a surprising finding as sexuality is considered a very private topic and women are more conservative about their sex-related issues. The same was reported in similar conservative cultures. ${ }^{20}$

Few reports assessed the validity of the Arabic version of the EORTC QLQ-C30 with or without the breast cancer-specific BR23 utilizing various methods and psychometric indices; for example, multitrait scaling analysis, convergent and discriminant validity of items, and known group comparison. ${ }^{12-17}$ However, none of these reports used factor analysis with the exception of the Lebanese study, which used confirmatory and not exploratory factor analysis. ${ }^{15}$ Therefore, in the present study, we focused on exploratory factor analysis to test the construct validity of the Arabic version of the QLQ-C30 and BR23 tool.
We conducted factor analysis to identify the nature of the factors underlying the set of measures in the questionnaire. Principle component analysis extracted four factors for the $\mathrm{C} 30$ tool. These Factors explained $51.52 \%$ of the total variance. Further, the analysis showed that all the items of physical and role functioning scale were loaded on one factor. This is consistent with studies conducted elsewhere ${ }^{21-23}$ and indicates that both the scales may not be separable. The fifth item of the physical functioning scale did not load factor one instead it clustered itself with the fourth factor. Similar problems with this item have been reported in the literature. ${ }^{23}$ In congruent with other studies, ${ }^{21}$ the second factor addressed the emotional issues of cancer patients and this was evident in the fact that this factor loaded all items of emotional scale. The third factor loaded pain, fatigue and cognitive scales. One of the 
possible explanations is that concentration problems might in fact be due to pain or fatigue rather than memory problems. Further, cognitive scale has consistently shown suboptimal Cronbach's alphas in the literature for various languages including Arabic. ${ }^{12-15,23,24}$

The fourth factor loaded appetite loss, nausea, vomiting, constipation and diarrhea in one factor. All are gastrointestinal symptoms and hence may be not separable as they are closely related in terms of their clinical presentation. The same was reported in other studies, ${ }^{21}$ which indicates that these scales are probably indivisible and best to be combined in one symptom scale. Item 28 (financial difficulties) did not load any of the factors which could be explained by the fact that health care including cancer treatment is free of charge for nationals in Bahrain and in most Arabian Gulf countries. ${ }^{25}$

For the BR23 tool, three factors were identified and they explained a total variance of $46.05 \%$. All items of body image were loaded on the first factor whereas items related to systemic side effects loaded the third factor. Items of arm and breast symptoms were loaded on the second factor, which indicates that they are closely related and may not be separable and would best be considered as one scale. Item 35 (hair loss) did not load in any of the factors and one possible explanation is that the study included women at different phases of their treatment journey whereas hair loss is usually experienced during the early stages of treatment. Other studies also reported the same issue with this item. ${ }^{20}$

One of the limitations is the rarity of this type of construct validity assessment in the studies examining the validity of the Arabic version of the QLQ-C30 and BR23 questionnaire. Therefore, the comparability of our result with other studies in the region becomes a challenging task. Another limitation is that some of the studies testing the validity of the Arabic version have used local spoken languages ${ }^{16}$ rather than the standard official Arabic language that was used in our study which might threaten the precision of our comparison.

\section{Conclusion}

This study revealed that the Arabic version of EORTC QLQ-C30 and its breast cancer-specific BR23 instrument is reliable and valid with some suggested modifications in some of the domains or items.

\section{Ethical Consideration}

Ethical approval was obtained from the ethics committees in the Royal College of Surgeons in Ireland-Medical University of Bahrain and the Ministry of Health in Bahrain. Participants provided written informed consent and they were given information sheets. Data were collected anonymously and presented collectively. We followed the guidelines outlined in the Declaration of Helsinki.

\section{Disclosure}

The authors report no conflicts of interest for this work.

\section{References}

1. Bray F, Ferlay J, Soerjomataram I, Siegel RL, Torre LA, Jemal A. Global cancer statistics 2018: GLOBOCAN estimates of incidence and mortality worldwide for 36 cancers in 185 countries. $C A$ Cancer J Clin. 2018;68(6):394-424.

2. Nayak MG, George A, Vidyasagar MS, et al. Quality of life among cancer patients. Indian J Palliat Care. 2017;23(4):445-450. doi:10.4103/IJPC.IJPC_82_17

3. Osoba D. Health-related quality of life and cancer clinical trials. Ther Adv Med Oncol. 2011;3(2):57-71. doi:10.1177/1758834010395342

4. Niu HY, Niu CY, Wang JH, Zhang Y, He P. Health-related quality of life in women with breast cancer: a literature-based review of psychometric properties of breast cancer-specific measures. Asian Pac J Cancer Prev. 2014;15(8):3533-3536. doi:10.7314/APJCP.2014.15.8.3533

5. Sprangers MA, Cull A, Groenvold M, Bjordal K, Blazeby J, Aaronson NK. The European Organization for research and treatment of cancer approach to developing questionnaire modules: an update and overview. EORTC Quality of Life Study Group. Qual Life Res. 1998;7(4):291-300. doi:10.1023/A:1008890401133

6. EORTC. Quality of life group website. Quality of life of cancer patients. 2020. Available from: https://qol.eortc.org/. Accessed September 11, 2020.

7. Jassim GA, Whitford DL. Quality of life of Bahraini women with breast cancer: a cross sectional study. BMC Cancer. 2013;13(1):212. doi:10.1186/1471-2407-13-212

8. Jassim GA, Whitford DL. Understanding the experiences and quality of life issues of Bahraini women with breast cancer. Soc Sci Med. 2014;107:189-195. doi:10.1016/j.socscimed.2014.01.031

9. El Saghir NS, Khalil MK, Eid T, et al. Trends in epidemiology and management of breast cancer in developing Arab countries: a literature and registry analysis. Int J Surg. 2007;5(4):225-233. doi:10.1016/j.ijsu.2006.06.015

10. Hamadeh RR, Abulfatih NM, Fekri MA, Al-Mehza HE. Epidemiology of breast cancer among Bahraini women: data from the Bahrain cancer registry. Sultan Qaboos Univ Med J. 2014;14(2):e176-e182.

11. Abu-Naser D. Arab women who have breast cancer face taboo. 2007. Available from: http://www.nbcnews.com/id/21455455/ns/health-cancer /t/breast-cancer-often-untreated-middle-east/. Accessed November 30, 2020.

12. Alawadhi SA, Ohaeri JU. Validity and reliability of the European Organization for Research and Treatment in Cancer Quality of Life Questionnaire (EORTC QLQ): experience from Kuwait using a sample of women with breast cancer. Ann Saudi Med. 2010;30 (5):390-396. doi:10.4103/0256-4947.67083

13. Awad MA, Denic S, El Taji H. Validation of the European Organization for research and treatment of cancer quality of life questionnaires for Arabic-speaking populations. Ann N Y Acad Sci. 2008;1138(1):146-154. doi:10.1196/annals.1414.021

14. Bener A, Alsulaiman R, Doodson L, El Ayoubi H. An assessment of reliability and validity of the European organization for research and treatment of cancer quality of life questionnaire C30 among breast cancer patients in Qatar. J Family Med Prim Care. 2017;6 (4):824-831. 
15. Huijer HA, Sagherian K, Tamim H. Validation of the Arabic version of the EORTC quality of life questionnaire among cancer patients in Lebanon. Qual Life Res. 2013;22(6):1473-1481. doi:10.1007/s11136012-0261-0

16. Nejjari C, El Fakir S, Bendahhou K, et al. Translation and validation of European organization for research and treatment of cancer quality of life questionnaire -C30 into moroccan version for cancer patients in Morocco. BMC Res Notes. 2014;7(1):228. doi:10.1186/1756-05007-228

17. El Fakir S, Abda N, Bendahhou K, et al. The European Organization for research and treatment of cancer quality of life questionnaire-BR23 breast cancer-specific quality of life questionnaire: psychometric properties in a Moroccan sample of breast cancer patients. BMC Res Notes. 2014;7:53. doi:10.1186/1756-0500-7-53

18. Kang HA. Guide on the use of factor analysis in the assessment of construct validity [article in Korean]. J Korean Acad Nurs. 2013;43 (5):587-594. doi:10.4040/jkan.2013.43.5.587

19. Stevens J. Applied Multivariate Statistics for the Social Sciences. Hillsdale, NJ: Lawrence Erlbaum Associates; 1986.

20. Chen Q, Li S, Wang M, Liu L, Chen G. Health-related quality of life among women breast cancer patients in Eastern China. J Biomed Res Int. 2018;2018(12).
21. Barman MP, Hazarika J, Kalita A. Reliability and validity of assamese version of EORTC QLQ-C30 questionnaire for studying the quality of life of cancer patients of Assam. World Appl Sci J. 2012;17 (5):672-678.

22. Guzelant A, Goksel T, Ozkok S, Tasbakan S, Aysan T, Bottomley A. The European Organization for research and treatment of cancer QLQ-C30: an examination into the cultural validity and reliability of the Turkish version of the EORTC QLQ-C30. Eur J Cancer Care. 2004;13(2):135-144. doi:10.1111/j.1365-2354.2003.00435.x

23. Lee E-H, Chun M, Wang H-J, Lim HY, Choi J-H. Multidimensional constructs of the EORTC Quality of Life Questionnaire (QLQ-C30) in Korean cancer patients with heterogeneous diagnoses. Cancer Res Treat. 2005;37(3):148-156. doi:10.4143/crt.2005.37.3.148

24. Kontodimopoulos N, Ntinoulis K, Niakas D. Validity of the Greek EORTC QLQ-C30 and QLQ-BR23 for measuring health-related quality of life in breast cancer patients. Eur J Cancer Care (Engl). 2011;20(3):354-361. doi:10.1111/j.1365-2354.2009.01170.x

25. World Health Organisation. Health system profile-Bahrain. 2007. Available from: http://apps.who.int/medicinedocs/documents/ s17291e/s17291e.pdf. Accessed March 3, 2019.

\section{Publish your work in this journal}

Neuropsychiatric Disease and Treatment is an international, peerreviewed journal of clinical therapeutics and pharmacology focusing on concise rapid reporting of clinical or pre-clinical studies on a range of neuropsychiatric and neurological disorders. This journal is indexed on PubMed Central, the 'PsycINFO' database and CAS, and is the official journal of The International Neuropsychiatric Association (INA). The manuscript management system is completely online and includes a very quick and fair peer-review system, which is all easy to use. Visit http://www.dovepress.com/testimonials.php to read real quotes from published authors. 